\title{
ESTRATÉGIA PARA REDUÇÃO DE MORTES NO TRÂNSITO DA CIDADE DE SÃO PAULO
}

\author{
Fernanda Luzia Cucick ${ }^{1}$, Giulia Tabarini Rodrigues ${ }^{1}$, Leonardo Vieira Matheus ${ }^{1} \mathrm{e}$ \\ Luiz Vicente Figueira de Mello Filho ${ }^{1}$ \\ ${ }^{1}$ Universidade Presbiteriana Mackenzie \\ E-mails: f.cucick@gmail.com, giuliarodrigues@ hotmail.com.br, \\ leonardo_vm10@hotmail.com e luiz.mello@mackenzie.br
}

\begin{abstract}
This study has as main aim to analyze and propose alternatives to reduce accidents, not necessarily in the number, but in the amount of fatalities and injuries in traffic in São Paulo city. The traffic accidents are the ninth largest cause of death in the world according to World Health Organization (WHO). On the global scene Brazil currently occupies the fifth place in traffic deaths, after India, China, USA and Russia. The National Congress recently changed 11 articles of Law No. 9503 of September 23, 1997, that establishing the Brazilian Traffic Code, in order to strengthen the penalty for traffic offenders to reduce the main causes of road accidents, including: speeding, alcohol, illegal racing and dangerous overtaking. However, in the Brazilian scenario, the measures taken do not reach the expected goal mainly due to factors such as lack of supervision by the authorities, shortage of educational campaigns and penalty for offenders. To conclude, this article demonstrates that the integration of systematic and combined measures of public policies for the health and lives of people may lead to a behavioral change in the long term, significantly reducing the number of deaths and lasting harm.
\end{abstract}

\section{RESUMO}

O estudo deste trabalho tem como principal objetivo analisar e propor alternativas para a redução de acidentes, não necessariamente no número, mas no montante de fatalidades e lesões no trânsito na cidade de São Paulo. Os acidentes de trânsito são a oitava maior causa de mortes no mundo conforme estudos da Organização Mundial da Saúde (OMS). No panorama mundial, o Brasil ocupa atualmente a quinta colocação entre os recordistas em mortes no trânsito, atrás apenas da Índia, China, Estados Unidos e Rússia. O Congresso Nacional alterou recentemente 11 artigos da Lei no 9.503, de 23 de setembro de 1997, que institui o Código de Trânsito Brasileiro, com o intuito de reforçar a penalidade dos infratores de trânsito, com o propósito de reduzir os principais focos causadores de acidentes viários, entre eles: excesso de velocidade, alcoolismo, corridas clandestinas e ultrapassagens perigosas. Porém, no cenário brasileiro, as medidas tomadas não alcançam o objetivo esperado devido, principalmente, a fatores como a falta de fiscalização por parte das autoridades, escassez de campanhas educativas e penalidade dos infratores. Para concluir, este artigo demonstra que a integração das medidas sistemáticas e combinadas de políticas públicas voltadas para a saúde e vida das pessoas, podem levar à uma transformação comportamental no trânsito a longo prazo, reduzindo significativamente o número de mortes e com "lesões permanentes". 


\section{INTRODUÇÃO}

Os acidentes de trânsito são a oitava maior causa de mortes no mundo conforme estudos da OMS (WHO, 2013). Estima-se que 1,3 milhão de pessoas morreram em acidentes de trânsito no ano de 2009 em 178 países e aproximadamente 50 milhões de pessoas sobreviveram com traumatismos e feridas (WAISELFISZ, 2012).

Em 2012, cerca de 3500 vidas foram perdidas em acidentes de trânsito, sendo este valor superior ao de $2000 \mathrm{em} 600$ casos. Com isso, esse tipo de morte entrou para o ranking das 10 principais causas de mortes de 2000 a 2012 (WHO, 2014). Sendo a faixa etária de 15 a 29 anos mais afetada, seguida pela faixa de 5 a 14 anos e por fim de 30 a 44 anos. No panorama mundial, o Brasil ocupa atualmente a quinta colocação entre os recordistas em mortes no trânsito, atrás apenas da Índia, China, Estados Unidos e Rússia (WHO, 2009,2013 apud FREITAS, 2013).

Segundo a OMS, a situação tende a se agravar nos próximos anos em países de baixa e média renda, por conta do crescimento progressivo dos índices de motorização e pela falta de planejamento e baixo investimento atual na estrutura das vias públicas. Se nada for feito, as mortes tendem a chegar a 1,9 milhão no ano de 2020, podendo passar de oitava para a quinta maior causa potencial de mortes até 2030 (OLIVEIRA, 2013).

As vítimas de acidentes viários são em sua maioria pessoas em idade ativa de acordo com a Comissão Regional das Nações Unidas. Além de causar grande perda humana, essas fatalidades e lesões resultadas dos acidentes de trânsito impõem um custo financeiro alto de centenas de milhares de dólares. Em países com pouco rendimento, esse valor ultrapassa a ajuda que recebem para seu desenvolvimento (2009 apud CAMPOS et al., 2013).

Figura 1: Proporção percentual das mortes por acidentes de transporte terrestre, segundo a faixa etária (20012010)

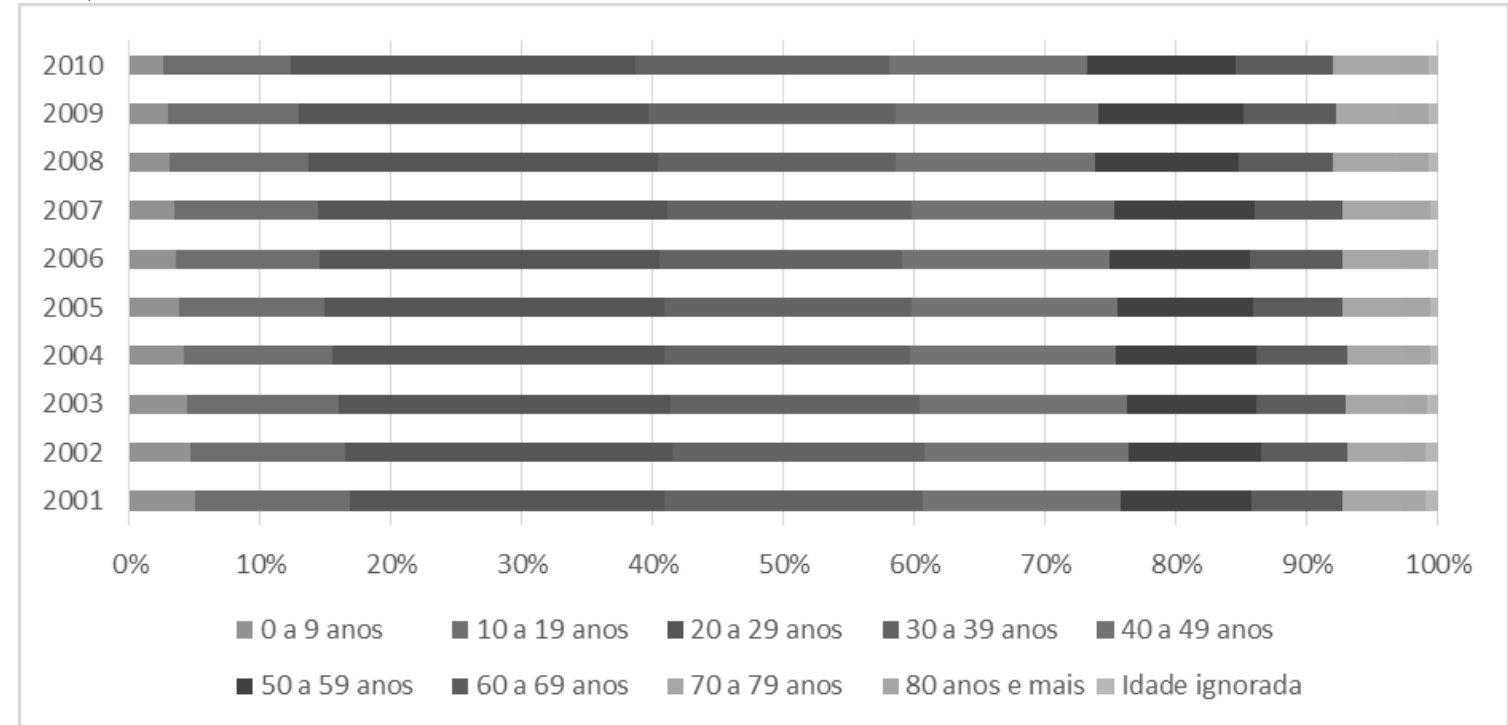

Fonte: ANTP - O panorama do Brasil anterior à Década de Ação pela Segurança Viária 2011-2020 - 2013

Em sua maioria, os acidentes são causados por fatores já conhecidos, como por exemplo, alta velocidade, embriaguez, não utilização de dispositivos de segurança, ultrapassagens perigosas e falta de respeito com os utilizadores vulneráveis das vias, incluindo pedestres e ciclistas. É 
possível lidar com esses fatores, porém é necessário preencher a lacuna entre o saber e o fazer (UNITED NATIONS, 2010).

\section{REVISÃO BIBLIOGRÁFICA}

Conforme a Organização Mundial da Saúde (2013), para que haja a redução do número de acidentes de trânsito, além dos esforços para cumprir metas e objetivos, é necessário um programa que deve ser feito em cinco pilares, sendo eles: gestão da segurança viária, vias mais seguras e mobilidade, veículos mais seguros, conscientização dos usuários e resposta ao acidente.

Figura 2 - Pilares para a Segurança Viária

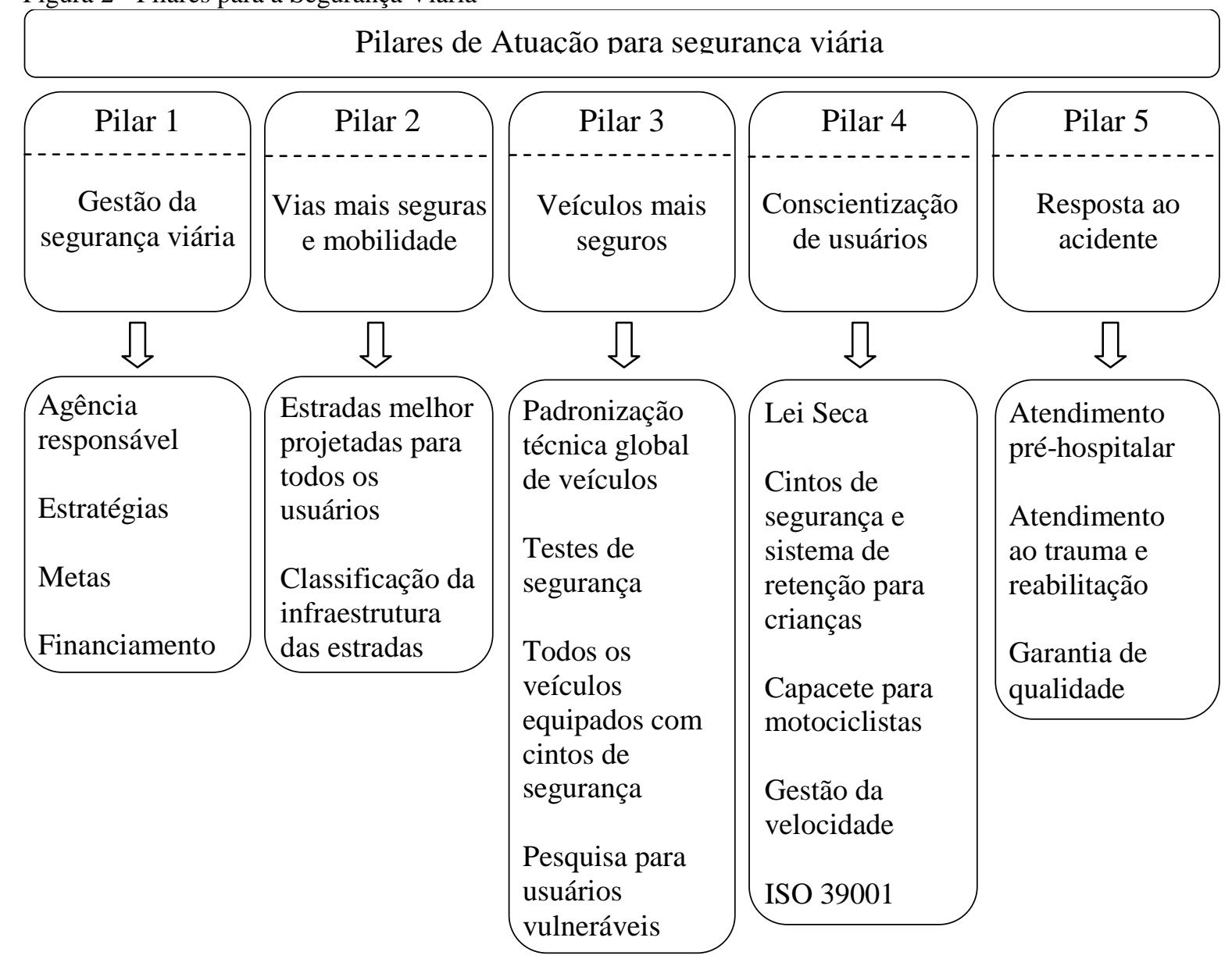

Fonte: Retrato da Segurança Viária no Brasil - 2014

O primeiro pilar atribui uma agência que seja responsável pelo controle e gerenciamento da segurança viária, por meio de metas e busca de suporte financeiro para realização de projetos. O segundo, busca um aprimoramento do planejamento das vias para que todos os usuários do sistema, principalmente os vulneráveis, como os pedestres, ciclistas e motociclistas, tenham garantia de uma infraestrutura segura. $O$ terceiro por sua vez, visa à padronização dos veículos, incluindo testes rígidos de segurança e desenvolvimento de veículos preparados com itens de segurança, como airbag e freio ABS (Anti-lock Breaking System - Sistema de freios anti-travamento), incluindo desenvolvimento com foco nos usuários vulneráveis. O quarto pilar visa à educação dos condutores em relação à utilização dos itens individuais de 
segurança, como cinto de segurança, capacete e cadeirinha (bebê conforto) para as crianças, além da adaptação das velocidades às vias e implantação da ISO39001, responsável pela identificação de práticas de segurança viária de sucesso. Por fim, o quinto pilar busca melhorar o atendimento pré-hospitalar, socorro pós-acidente e reabilitação dos usuários que sofreram acidente (AMBEV S.A, 2014).

Segundo Ferrraz, Raia Jr e Bezerra (2008 apud Raia Jr; 2009), há quatro fatores que contribuem para a ocorrência dos acidentes de trânsito, que são: os condutores, os veículos, a velocidade e a via, e seu entorno.

Em relação aos condutores há alguns aspectos relevantes, como por exemplo, ter consciência da utilização correta dos equipamentos de segurança e respeitar as regras de trânsito como o limite de velocidade e lei seca, seguindo esses aspectos, o condutor contribui para a redução do risco dos acidentes. Segundo o programa Visão Zero, até mesmo os condutores mais experientes estão sujeitos ao erro e isso deve ser levado em consideração para estruturar um sistema de tráfego (RAIA JUNIOR; SANTOS, 2005).

Mesmo com o aprimoramento de novas tecnologias voltadas a segurança, as pessoas não podem contar $100 \%$ com os sistemas de proteção dos veículos, pois muitos dos acidentes acontecem em velocidades extremamente altas, que impossibilitam o próprio veículo de absorver as forças do impacto as quais os ocupantes estão sujeitos, são essas as forças que podem levar à morte ou lesões graves (RAIA JUNIOR, 2009).

Os danos mais graves são aqueles que ocorrem quando o veículo colide frontalmente ou lateralmente com objetos rígidos, como por exemplo, árvores, postes, gradios, entre outros, que estão localizados na via ou em seu entorno. Para tanto, as vias e laterais devem ser projetadas com intuito de mitigar ou até mesmo eliminar a ocorrência dessas colisões, de maneira que quando houver uma colisão, a força de impacto possa ser absorvida pelo veículo e seus sistemas de segurança, sem prejudicar os ocupantes. As alternativas para minimizar tais tipos de colisões são barreiras que evitem que os veículos sejam projetados para fora da pista, no sentido contrário ou até mesmo em um barranco. (RAIA JUNIOR; SANTOS, 2005).

Os sistemas de tráfego estarão sempre sujeitos aos acidentes, uma vez que nem todos os erros dos usuários do sistema podem ser eliminados. Os resultados das colisões e acidentes devem ser bastante reduzidos por operações de resgate, absorção e redução dos impactos por parte da infraestrutura do sistema. (RAIA JUNIOR; SANTOS, 2005).

Segundo o programa Visão Zero a velocidade é um ponto que pode ser aprimorado para compensar as negligencias de segurança nos sistemas de trânsito. A velocidade é o fator mais significante na segurança viária, e é importante conhecer a quantidade transferida de energia em uma colisão para controlar a velocidade em que se pode trafegar nos determinados sistemas projetados. (RAIA JUNIOR, 2009)

Uma das formas para que seja possível atingir o ponto ótimo na engenharia de tráfego, devese levar em consideração a maior fluidez, conforto e segurança. Para isso há três eixos, que devem ser analisados com atenção: infraestrutura, educação e fiscalização, conhecido também como 3E nos Estados Unidos: engineering, education e enforcement (MELLO FILHO, 2014). 
É fundamental a educação para o trânsito no lar, na escola e mais ainda para os condutores dos veículos, pois cada cidadão tem de saber qual é a sua responsabilidade para a construção de um trânsito seguro para todos. Como diz Monte (2003 apud ROCHA e SILVEIRA 2013) "em termos de Educação de Trânsito o nosso país ainda se encontra engatinhando".

A engenharia ou infraestrutura, é responsável pela segurança, fluidez do tráfego e evolução tecnológica dos veículo. Sendo assim, toda a confiança ao dirigir é depositada na infraestrutura que é disponibilizada ao usuário, este por sua vez espera vias em boas condições de conservação e veículos com evolução tecnológica que tenha segurança (FRANZ e SEBERINO, 2012). Por fim, temos a fiscalização, que se refere tanto ao monitoramento dos usuários quanto á inspeção dos veículos, visando um trânsito em condições seguras.

Os três programas internacionais que são citados neste estudo focam seus esforços para deixar os $3 \mathrm{E}$ bem estruturados, para assim conseguir atingir o objetivos dos programas, que é a redução de mortes no trânsito, mantendo-se o fluxo de carros nas vias com a devida segurança.

\subsection{PROGRAMAS INTERNACIONAIS}

Iniciado na Suécia em 1977, o programa Visão Zero tem como base o princípio de que "nenhuma vida perdida no trânsito é moralmente aceitável". Este programa divide a responsabilidade pelos acidentes de trânsito entre usuários, projetistas e gestores do sistema viário (LINDAU; OBELHEIRO; MACHADO, 2015). Além disso, segundo Atkins e Granhed (2012) o programa tem algumas visões diferentes em relação a outros programas que visam à redução das fatalidades por acidentes de trânsito.

Tabela 1 - Comparativo do pensamento tradicional com o programa Visão Zero

\begin{tabular}{|c|c|}
\hline $\begin{array}{c}\text { Pensamento dos tradicionais } \\
\text { programas }\end{array}$ & Visão Zero \\
\hline Foco no acidente & Foco em morte e em feridos \\
\hline $\begin{array}{c}\text { Forças excessivas mecânicas para } \\
\text { humanos }\end{array}$ & $\begin{array}{c}\text { Diminuição de forças mecânicas } \\
\text { para a tolerância humana }\end{array}$ \\
\hline Perfeito comportamento humano & Considera-se falhas humanas \\
\hline $\begin{array}{c}\text { Aplicação e educação - estudo } \\
\text { como precaução da morte }\end{array}$ & $\begin{array}{c}\text { Aplicação e educação - estudo da } \\
\text { demanda que seria ideal para não } \\
\text { ter acidente }\end{array}$ \\
\hline Responsabilidade individual & Responsabilidade dividida \\
\hline $\begin{array}{c}\text { Pessoas não se importam com } \\
\text { segurança }\end{array}$ & Pessoas procuram segurança \\
\hline Riscos aceitáveis & Riscos inaceitáveis \\
\hline Soluções estratégicas individuais & Múltiplas combinações de soluções \\
estratégicas
\end{tabular}

Fonte: Vision zero: Applying road safety to avalanche safety - 2012 
O programa The Vision Zero (2015), tem como meta reduzir à zero o número de acidentes de trânsito fatais em longo prazo. A mentalidade do programa consiste em colocar a responsabilidade sobre os acidentes de trânsito no sistema viário utilizado, uma vez que este reconhece as fraquezas humanas e baixa tolerância às forças mecânicas. Para um sistema seguro é essencial à contribuição de comportamento humano seguro, educação e fiscalização.

Segundo Raia Junior (2009) a Organização Mundial de Saúde (OMS) a filosofia do programa pode ser utilizada em qualquer país que tenha como objetivo minimizar o número de acidentes fatais em seu território, já que seus princípios básicos são aplicáveis a qualquer estágio de desenvolvimento de sistemas viários.

A seguir são apresentados os pontos do programa Visão Zero de maior relevância implantada para a redução de mortes e sequelas permanentes no trânsito.

Os serviços públicos como a fiscalização e educação são vitais para que haja sucesso na implantação de soluções eficazes de segurança no tráfego. As áreas de foco variam entre a educação do motorista e o planejamento a nível nacional. É necessário que haja sistema de controle e vigilância de tráfego, fluxos e até as condições climáticas para que se tenha um sistema de tráfego considerável.

Segundo Tingvall e Haworth (1999), a tolerância humana para um atropelamento por um automóvel está relacionada a uma velocidade de $30 \mathrm{kM} / \mathrm{H}$, caso a velocidade tenha de ser maior, é necessário que os pedestres tenham sua via separada do tráfego de veículos. O mesmo é valido para colisões entre automóveis onde os limites são 70 $\mathrm{kM} / \mathrm{H}$ para colisões frontais e $50 \mathrm{kM} / \mathrm{H}$ para colisões laterais. Velocidades superiores só podem ser consideradas se a interface entre usuário e infraestrutura estiver bem desenhada. Com base nessa visão de limites de velocidades permitidas, o programa Visão Zero estabelece os limites de velocidades em cada tipo de vias como pode ser analisado na tabela a seguir.

Tabela 2 - Velocidade ideal das vias em relação com a infraestrutura

\begin{tabular}{|l|c|}
\hline \multicolumn{1}{|c|}{ Tipo de infraestrutura e tráfico } & Velocidade Aceitável \\
\hline $\begin{array}{l}\text { Locais com possibilidade de conflitos entre } \\
\text { pedestres e carros }\end{array}$ & $30 \mathrm{Km} / \mathrm{h}$ \\
\hline $\begin{array}{l}\text { Interseções com possibilidade de impactos entre } \\
\text { carros }\end{array}$ & $50 \mathrm{Km} / \mathrm{h}$ \\
\hline $\begin{array}{l}\text { Estradas com possibilidades de impactos frontais } \\
\text { entre carros }\end{array}$ & $70 \mathrm{~km} / \mathrm{h}$ \\
\hline $\begin{array}{l}\text { Estradas sem possibilidade de impactos laterais ou } \\
\text { frontais, apenas impactos com infraestruturas. }\end{array}$ & $+100 \mathrm{Km} / \mathrm{h}$ \\
\hline
\end{tabular}

Segundo relatório do IRTAD (2014), desde o final dos anos 1990, o programa Visão Zero na Suécia conseguiu reduzir por volta de $60 \%$ o número de fatalidades no trânsito, sendo o país com menor índice do mundo de fatalidades desse tipo, enquanto o número de lesões reduziu apenas 3\%. Em 2012, 285 pessoas morreram em acidentes de trânsito, um decréscimo de aproximadamente $11 \%$ em relação a 2011. O número de mortes caiu para todos os usuários das vias, exceto para os 
ciclistas. A configuração dos acidentes de trânsito na Suécia em 2012 é composta por $60 \%$ de acidentes em estradas rurais, $31 \%$ nas zonas urbanas e $6 \%$ nas auto-estradas. Para o programa The Vision Zero (2015), o volume de tráfego e as taxas de mortalidade, são diretamente ligados ao crescimento econômico, porém é possível notar que as fatalidades nas vias têm sido reduzidas mesmo com o aumento constante no tráfego.

Na cidade de Nova York este programa também foi implantado. Segundo o programa Visão Zero Nova York, aproximadamente 4.000 nova-iorquinos sofrem sérios acidentes a cada ano e mais de 250 são mortos em acidentes veiculares, sendo que $56 \%$ são pedestres. Com o programa a infraestrutura está sendo mudada com reconstruções e redesenho de avenidas para aumentar a segurança, com uso de faixas exclusivas para ônibus, ciclistas e criação de faixa de pedestres. Também, remoção de barreiras visuais e aumento de visibilidades com a utilização de maior número de pontos com iluminação durante a noite.

Referente à fiscalização houve uma redução da velocidade permitida em toda a cidade para $25 \mathrm{MPH}(40 \mathrm{kM} / \mathrm{H})$, aumento de radares de velocidade nas principais vias da cidade e aumento das penas com leis mais vigorosas para conduções perigosas (New York DOT, 2014). É imprescindível para o plano a cooperação entre os cidadãos e os órgãos públicos, além de educar os motoristas com palestras, cursos na comunidade e campanhas públicas (Vision Zero New York, 2014).

O outro sistema conhecido é o Sistema de Segurança Sustentável, introduzido nos Países Baixos, é um programa que busca prevenir os acidentes e, na impossibilidade de prevenir, procura minimizar seus danos e consequências aos condutores. $\mathrm{O}$ programa se baseia na ideia de que as pessoas cometem erros e são fisicamente vulneráveis a eles. Sendo assim, é necessária a apresentação de cinco princípios fundamentais: funcionalidade, por meio de vias, de distribuição e acesso em rede, formando um elo rodoviário estruturado hierarquicamente; a homogeneidade; igualdade da velocidade, direção, e conjunto de médias e máximas velocidades; a previsibilidade, o respeito do curso da via, tendo um comportamento mais seguro devido ao design de via reconhecível; a generosidade, diminuição das lesões por meio de um ambiente rodoviário em que o usuário mais experiente possua uma postura mais defensiva e preventiva com os usuários menos experientes; a sensibilização do estado, habilidade do estado em garantir a capacidade de condução do condutor. (INSTITUTE FOR ROAD SAFETY RESEARCH, 2006).

A visão de Segurança Sustentável, segundo o relatório do Institute for Road Safety Research (2006) influencia largamente a prática de segurança rodoviária, conduzindo à aplicação de medidas de segurança eficazes e sustentáveis, ela tem sido a principal da política de segurança rodoviária dos Países Baixos desde o início dos anos 1990. Cabe às autoridades rodoviárias, tanto a nível nacional como regional e local, executarem as medidas de Segurança Sustentável.

Estima-se a eficiência relativa à implantação das medidas adotadas em infraestrutura, e também da abordagem de segurança sustentável permitiram reduzir em $6 \%$ o número de mortes e internamentos a nível nacional. Os custos, particularmente os relacionados com a reconstrução rodoviária, são elevados, embora possam ser 
combinados com o orçamento para obras de manutenção regulares (INSTITUTE FOR ROAD SAFETY RESEARCH, 2006).

Segundo Winkelbauer (2010), a conversão de um cruzamento normal em rotatórias permite reduzir os acidentes com ferimentos em $32 \%$ e $41 \%$, comparando com os cruzamentos de três e quatro vias respectivamente. Estas percentagens são de $11 \% \mathrm{e}$ $17 \%$, respectivamente, quando um cruzamento sinalizado é transformado em rotatórias. A relação custo-benefício a partir do indicador de rentabilidade, que se destina em medir o potencial que o negócio tem em se pagar, com base no investimento realizado em sua aquisição ou estruturação. Se o indicador for maior que 1 o projeto é rentável. Quando o indicador é cerca de 2, um cruzamento típico de três ou quatro vias é convertido em rotatórias.

Outra ação para a visão de Segurança Sustentável está nos condutores de veículos, que independentemente do meio utilizado, cometem erros inadvertidamente e infrações intencionalmente. Ambos resultam em comportamentos de condução insegura. Por este motivo, há recursos de bloqueios, principalmente nos automóveis, que impedem os condutores de usar o automóvel sempre que o não esteja apto a dirigir. Por exemplo, por meio de um cartão inteligente. É uma alternativa que impede o condutor em dirigir o veículo se a licença de condução estiver apreendida ou em caso de restrições de condução específicas (WINKELBAUER, 2010).

O bloqueio da ignição por alcoolemia ou o Alcolock é um dispositivo eletrônico que impede a partida do veículo caso o condutor tenha uma taxa de alcoolemia acima do permitido. Para medir o nível de álcool no sangue, o condutor sopra um dispositivo antes da ignição do motor e, posteriormente, em diferentes momentos da condução. Em termos gerais, o dispositivo impede a reincidência de condutores condenados por conduzir sob o efeito do álcool. Em tais casos o Alcolock faz parte de um programa de prevenção, que inclui apoio médico e psicológico (NEVE, 2013).

Os programas Alcolock para infratores é uma alternativa para o Brasil, que pode iniciar em grandes centros, mas é necessário ser legislado. Merece, também, o apoio de entidade responsável pela sua instalação e pela leitura dos dados, e outra entidade, para avaliar os resultados e prestar acompanhamento médico e psicológico aos condutores com Alcolock. O risco de colisão com feridos em automóveis equipados com Alcolock diminui cerca de 50\%. Calcula-se ainda que os Alcolocks resultem numa redução de 40-95 \% da taxa de reincidência em condutores condenados por conduzirem sob o efeito de álcool. (NEVE, 2013)

E por último, a escola "Seef", segundo School Op Seef (2015) é um programa Holandês para uma abordagem eficaz para a segurança rodoviária e educação no trânsito para crianças em idade escolar primária. As crianças estão em um ambiente seguro de uma forma contemporânea guiada no seu desenvolvimento de forma sustentável para os usuários de rodovias seguras. Incluem alta qualidade e material atraente, prático e digital. A Escola de programa "Seef" oferece a possibilidade de diferentes aspectos de educação, infraestrutura, comunicações, entre outros, a cooperar. O lema é: "As crianças têm direito a um ambiente seguro, de forma tão independente quanto a possível participação no tráfego". 
As partes que estão envolvidas nesse projeto abrangem as esferas: escolares, os municípios, a polícia local, organizações de segurança rodoviária e ainda os pais dos alunos. Há uma comissão independente que visita as escolas para prestar aconselhamento, apoio e que gere o processo de certificação e rotulagem (SCHOOL OP SEEF, 2015).

O estudo de avaliação, segundo School Op Seef (2015), abreviado sobre o programa "Seef' aponta para um pequeno efeito positivo sobre o comportamento de trânsito (auto-relatado). A participação das escolas é gratuita. As autoridades regionais oferecem apoio financeiro para a organização do projeto global e para materiais pedagógicos.

Os jovens condutores inexperientes correm um risco maior de se envolverem em acidentes do que os condutores mais velhos e mais experientes. $O$ ensino da condução constitui um bom instrumento para preparar as pessoas para uma condução segura e para uma maior consciência dos riscos envolvidos na condução de veículos automóveis (SCHOOL OP SEEF, 2015).

A partir deste programa, foi desenvolvido outro chamado "Reclama!", cujo público alvo é o jovem com idades entre os 16 e os 19 anos que viajam de automóvel como passageiros ao entardecer, à noite e durante o fim de semana. O "Reclama!" incentiva estes jovens a se manifestar se o condutor não estiver a conduzir com segurança. Por exemplo, se exceder o limite de velocidade ou conduzir sob o efeito de álcool ou drogas. Normalmente os jovens têm receio de dizer o que pensam por causa da pressão que sofrem dos pares. A informação e as mensagens são divulgadas durante as visitas às escolas e junto aos balcões de informação nas escolas, bem como a ajuda de filmes de vídeo e camisas. O controle vem reforçar as atividades de comunicação. O objetivo consiste em apoiar jovens com uma atitude positiva para denunciarem, controlarem e recriminarem aqueles com maiores probabilidades de não serem influenciados pela campanha. Os controles são efetuados em postos de controle por autoridades policiais (WINKELBAUER, 2010).

A avaliação dos primeiros três anos apontou para uma redução considerável no número de passageiros mortos ou feridos na faixa etária dos 16-19 anos: 27\% no primeiro ano, $31 \%$ no segundo ano e $36 \%$ no terceiro ano segundo o relatório desenvolvido por Astrid H Amundsen sobre os resultados do "Speak out!" no condado de Sogn og Fjordane (INSTITUTE FOR ROAD SAFETY RESEARCH, 2006).

\subsection{CENÁRIO BRASILEIRO}

No Brasil, os acidentes de trânsito ainda proporcionam uma grande quantidade de vidas perdidas anualmente. Atualmente o país ocupa o quinto maior índice no número de causas de mortes de trânsito.

Segundos dados do Ministério da Saúde, em 2012 foram mais de 44.800 mortos em acidentes e cerca de 179.000 feridos (POR VIAS SEGURAS, 2014). Estes números 
desproporcionais impressionam pela quantidade, já que matam mais que muitas doenças tropicais que atingem a população brasileira.

A importância da segurança viária no Brasil ainda tem um pequeno espaço no cenário político-social, embora as recentes ações aprovadas no Congresso Nacional que alteram diversos artigos do código de trânsito brasileiro, aumentando o rigor na punição de infratores de trânsito lei 12.971/14, cujo intuito é diminuir as principais condutas causadoras de mortes, tais como: alcoolismo, disputa de rachas e ultrapassagens perigosas (SOUZA; TEIXEIRA; TUMA JUNIOR, 2014).

Em 2014, 1.249 pessoas morreram e 441 ficaram feridas em acidentes de trânsito na cidade de São Paulo, segundo a CET, com base nos registros do Instituto Médico Legal - IML. O número de mortos cresceu 8,4\% em 2014 em relação a 2013, foi o primeiro aumento desde 2011. Dentre as principais vítimas fatais no trânsito na cidade, os pedestres concentram o maior índice, com 46,1\% de óbitos, seguidos pelos motociclistas com $36,1 \%$, motoristas/passageiros com $17,9 \%$ e pelos ciclistas com 3,1\%, segundo dados da Companhia de Engenharia de Tráfego (PAULA, 2014). Trata-se de uma perda significante de riqueza humana e materias que acontece todos os anos. Por este motivo é necessário tomar medidas que minimizem tantos acidentes e perdas.

Na cidade de São Paulo as medidas que são tomadas para redução do número de feridos e mortos, não surtem os efeitos esperados devido a fatores, principalmente, intrínsecos as autoridades, como a falta de fiscalização, incentivo a campanhas educativas e punição dos infratores.

\section{RESULTADOS DOS PROGRAMAS AVALIADOS}

Os programas estudados tiveram em sua maioria início nos anos 1990, com excessão do Vision Zero de Nova York que teve início em 2000. A partir do ano em que o projeto começou, houve uma redução significativa do número de mortes como pode ser observado nas tabelas a seguir.

Tabela 3 - Redução de mortes por tipo de usuários nos países estudados

\begin{tabular}{|l|c|c|c|c|c|c|c|}
\hline \multicolumn{3}{|c|}{ Mortes no trânsito por grupo - Nova York } & \multicolumn{3}{c|}{ \% Mudanças referente a 2014} \\
\hline Anos & $\mathbf{2 0 0 0}$ & $\mathbf{2 0 0 5}$ & $\mathbf{2 0 1 0}$ & $\mathbf{2 0 1 4}$ & $\mathbf{2 0 1 0}$ & $\mathbf{2 0 0 5}$ & $\mathbf{2 0 0 0}$ \\
\hline Bicicleta & 19 & 22 & 19 & 20 & $5,26 \%$ & $-9,09 \%$ & $5,26 \%$ \\
\hline Moto & 31 & 34 & 39 & 37 & $-5,13 \%$ & $8,82 \%$ & $19,35 \%$ \\
\hline Passageiros de veículos & 143 & 108 & 61 & 60 & $-1,64 \%$ & $-44,44 \%$ & $-58,04 \%$ \\
\hline Pedestres & 188 & 155 & 152 & 138 & $-9,21 \%$ & $-10,97 \%$ & $-26,60 \%$ \\
\hline \multicolumn{1}{|c|}{ TOTAL } & $\mathbf{3 8 1}$ & $\mathbf{3 1 9}$ & $\mathbf{2 7 1}$ & $\mathbf{2 5 5}$ & $-5,90 \%$ & $-20,06 \%$ & $-33,07 \%$ \\
\hline
\end{tabular}

Fonte: Vision Zero: One Year Report (2015) 


\begin{tabular}{|c|c|c|c|c|c|c|c|}
\hline \multicolumn{5}{|c|}{ Mortes no trânsito por grupo - Suécia } & \multicolumn{3}{|c|}{ \% Mudanças referente a 2012} \\
\hline Anos & 1990 & 2000 & 2011 & 2012 & 2011 & 2000 & 1990 \\
\hline Bicicleta & 68 & 47 & 21 & 28 & $33,33 \%$ & $-40,43 \%$ & $-58,82 \%$ \\
\hline Moto & 46 & 39 & 46 & 31 & $-32,61 \%$ & $-20,51 \%$ & $-32,61 \%$ \\
\hline Passageiros de veículos & 468 & 393 & 159 & 142 & $-10,69 \%$ & $-63,87 \%$ & $-69,66 \%$ \\
\hline Pedestres & 134 & 73 & 53 & 50 & $-5,66 \%$ & $-31,51 \%$ & $-62,69 \%$ \\
\hline TOTAL & 716 & 552 & 279 & 251 & $-10,04 \%$ & $-54,53 \%$ & $-64,94 \%$ \\
\hline
\end{tabular}

Fonte: IRTAD - Suécia Road Safety Annual Report (2014)

\begin{tabular}{|l|c|c|c|c|c|c|c|}
\hline \multicolumn{4}{|c|}{ Mortes no trânsito por grupo - Bélgica } & \multicolumn{3}{c|}{ \% Mudanças referente a 2012} \\
\hline Anos & $\mathbf{1 9 9 0}$ & $\mathbf{2 0 0 0}$ & $\mathbf{2 0 1 1}$ & $\mathbf{2 0 1 2}$ & $\mathbf{2 0 1 1}$ & $\mathbf{2 0 0 0}$ & $\mathbf{1 9 9 0}$ \\
\hline Bicicleta & 196 & 134 & 69 & 68 & $-1,45 \%$ & $-49,25 \%$ & $-65,31 \%$ \\
\hline Moto & 106 & 118 & 127 & 87 & $-31,50 \%$ & $-26,27 \%$ & $-17,92 \%$ \\
\hline Passageiros de veículos & 1181 & 922 & 458 & 384 & $-16,16 \%$ & $-58,35 \%$ & $-67,49 \%$ \\
\hline Pedestres & 301 & 142 & 113 & 104 & $-7,96 \%$ & $-26,76 \%$ & $-65,45 \%$ \\
\hline \multicolumn{1}{|c|}{ TOTAL } & $\mathbf{1 7 8 4}$ & $\mathbf{1 3 1 6}$ & $\mathbf{7 6 7}$ & $\mathbf{6 4 3}$ & $\mathbf{- 1 6 , 1 7 \%}$ & $\mathbf{- 5 1 , 1 4 \%}$ & $\mathbf{- 6 3 , 9 6 \%}$ \\
\hline
\end{tabular}

Fonte: IRTAD - Bélgica Road Safety Annual Report (2014)

\begin{tabular}{|l|c|c|c|c|c|c|c|}
\hline \multicolumn{9}{|c|}{ Mortes no trânsito por grupo - Luxemburgo } & \multicolumn{3}{c|}{ \% Mudanças referente a 2012} \\
\hline Anos & $\mathbf{1 9 9 0}$ & $\mathbf{2 0 0 0}$ & $\mathbf{2 0 1 1}$ & $\mathbf{2 0 1 2}$ & $\mathbf{2 0 1 1}$ & $\mathbf{2 0 0 0}$ & $\mathbf{1 9 9 0}$ \\
\hline Bicicleta & 1 & 1 & 1 & 0 & $-100,00 \%$ & $-100,00 \%$ & $-100,00 \%$ \\
\hline Moto & 8 & 8 & 3 & 5 & $66,67 \%$ & $-37,50 \%$ & $-37,50 \%$ \\
\hline Passageiros de veículos & 51 & 53 & 21 & 22 & $4,76 \%$ & $-58,49 \%$ & $-56,86 \%$ \\
\hline Pedestres & 10 & 11 & 6 & 6 & $0,00 \%$ & $-45,45 \%$ & $-40,00 \%$ \\
\hline \multicolumn{1}{|c|}{ TOTAL } & $\mathbf{7 0}$ & $\mathbf{7 3}$ & $\mathbf{3 1}$ & $\mathbf{3 3}$ & $\mathbf{6 , 4 5 \%}$ & $\mathbf{- 5 4 , 7 9 \%}$ & $\mathbf{- 5 2 , 8 6 \%}$ \\
\hline
\end{tabular}

Fonte: IRTAD - Luxemburgo Road Safety Annual Report (2014)

\begin{tabular}{|l|c|c|c|c|c|c|c|}
\hline \multicolumn{5}{|c|}{ Mortes no trânsito por grupo - Holanda } & \multicolumn{3}{c|}{ \% Mudanças referente a 2012} \\
\hline Anos & $\mathbf{1 9 9 0}$ & $\mathbf{2 0 0 0}$ & $\mathbf{2 0 1 1}$ & $\mathbf{2 0 1 2}$ & $\mathbf{2 0 1 1}$ & $\mathbf{2 0 0 0}$ & $\mathbf{1 9 9 0}$ \\
\hline Bicicleta & 304 & 233 & 200 & 200 & $0,00 \%$ & $-14,16 \%$ & $-34,21 \%$ \\
\hline Moto & 72 & 95 & 52 & 54 & $3,85 \%$ & $-43,16 \%$ & $-25,00 \%$ \\
\hline Passageiros de veículos & 702 & 543 & 231 & 232 & $0,43 \%$ & $-57,27 \%$ & $-66,95 \%$ \\
\hline Pedestres & 144 & 114 & 74 & 68 & $-8,11 \%$ & $-40,35 \%$ & $-52,78 \%$ \\
\hline \multicolumn{1}{|c|}{ TOTAL } & $\mathbf{1 2 2 2}$ & $\mathbf{9 8 5}$ & $\mathbf{5 5 7}$ & $\mathbf{5 5 4}$ & $\mathbf{- 0 , 5 4 \%}$ & $\mathbf{- 4 3 , 7 6 \%}$ & $\mathbf{- 5 4 , 6 6 \%}$ \\
\hline
\end{tabular}

Fonte: IRTAD - Holanda Road Safety Annual Report (2014)

Analisando as tabelas anteriores, é possivel notar que mesmo não tendo em alguns anos uma grande redução em um tipo de modalidade de transporte, como por exemplo, o índice de mortes de ciclistas em Nova York em 2010 comparado com 2014 ou o da Suécia em 2011 comparado com 2012, pode-se perceber que no geral das mortes, houve redução do índice naquele ano.

\section{APLICAÇÃO EM SÃO PAULO DOS PROGRAMAS INTERNACIONAIS}

Na cidade de São Paulo, segundo a CET (2014), 44,4\% das vítimas do trânsito na cidade eram pedestres, $16,6 \%$ eram motoristas e/ou passageiros, $35,2 \%$ motociclistas e $3,8 \%$ ciclistas. A vulnerabilidade dos pedestres é a principal causa deste elevado percentual, já que não 
possuem acessórios e equipamentos de proteção como os motoristas e passageiros, excluindo os ciclistas e motociclistas.

Em relação ao tipo do acidente, de um total de 1195 fatais ocorridos em 2014, segundo dados da CET (2014), 45\% dos acidentes foram causados por atropelamentos, 28,3\% por colisão, $15,8 \%$ por choque e $10,9 \%$ por causas não mensuradas.

Por volta de 189 acidentes fatais foram provenientes de choques, desses acidentes o índice que se apresentou maior foi o de choques contra postes $(40,2 \%)$ e muros $(20,1 \%)$. Segundo o pensamento do programa Visão Zero (RAIA JUNIOR, 2009), as vias e seu entorno devem ser projetadas evitando fortes colisões e absolvendo as forças de um impacto pelos veículos e seus sistemas de proteção, pois os mais sérios danos fisícos ocorrem quando o impacto do veículo é com uma superfície rígida. Como medidas de proteção barreiras podem ser utilizadas evitando a projeção do veículo para a outra via, a remoção de objetos como poste, árvores e estruturas de pórticos e placas, cabos de aço que separam as pistas são objetos que potencializam a gravidade do acidente.

Dos programas estudados, o que melhor se adequa para ser tomado como base de um programa para redução de acidentes de trânsito na cidade de São Paulo é o Vision Zero de Nova York, visto que ele tem como base o programa que foi iniciado na Suécia e que até então está gerando resultados positivos, que é uma cidade que comparada com a Suécia tem características diferentes, porém na questão de população e trânsito é semelhante à cidade de São Paulo. Com isso, quando bem aplicadas, as práticas relacionadas ao programa têm grandes chances de surtirem efeitos positivos em São Paulo.

Em relação ao programa aplicado em Nova York seria viável a aplicação da redução do limite de velocidade das vias para $40 \mathrm{kM} / \mathrm{H}$, visto que se um indivíduo for atingido por um veículo nesta velocidade, a chance de sobreviver é de $80 \%$, enquanto que a $65 \mathrm{kM} / \mathrm{H}$ a chance de morte é de $70 \%$.

Com a análise da redução significativa do número de mortos e feridos após a aplicação do programa Visão Zero em Nova York, é possível analisar hipoteticamente quais as mudanças possíveis para aplicação na cidade de São Paulo para surtirem efeito positivo.

Como já descrito, o relatório da CET (2014) apresentam os números de acidentes fatais somando um total de 1195, porém com um total de mortes de 1249. Os dados do relatório mostram ainda os números de acidentes fatais com relação ao tipo de usuário conforme a tabela a seguir. 
Tabela 4 - Acidentes de São Paulo

\begin{tabular}{|c|c|c|c|c|c|}
\hline & \multicolumn{4}{|c|}{ Tipo dos acidentes } \\
\hline & & Atropelamento & Choque & Colisão & Total \\
\hline \multicolumn{2}{|c|}{$\mathrm{N}$ de acidentes fatais em 2014} & 538 & 189 & 338 & 1195 \\
\hline \multirow{4}{*}{ Vítimas Mortas } & Pedestres & 537 & 8 & 8 & 555 \\
\hline & Motor./Passag. & 1 & 104 & 80 & 207 \\
\hline & Motociclistas & 9 & 92 & 243 & 440 \\
\hline & Ciclistas & 0 & 0 & 35 & 47 \\
\hline \multicolumn{2}{|c|}{ Total de mortes } & 547 & 204 & 366 & 1249 \\
\hline \multirow{4}{*}{ Vítimas Feridas } & Pedestres & 64 & 3 & 3 & 70 \\
\hline & Motor./Passag. & 15 & 96 & 100 & 221 \\
\hline & Motociclistas & 35 & 18 & 77 & 149 \\
\hline & Ciclistas & 0 & 0 & 1 & 1 \\
\hline \multicolumn{2}{|c|}{ Total de feridos } & 114 & 117 & 181 & 441 \\
\hline
\end{tabular}

Fonte: CET - Acidentes de Trânsito Fatais (2014)

Fazendo uma média aritmética com os dados dos três anos do programa Visão Zero de Nova York apresentados anteriormente na Tabela 3, podemos observar que houve redução de mortes na maioria das modalidades de transporte. Os motociclistas ficaram com um índice positivo, ou seja, por meio desta média, aparentemente, o índice de mortes de motociclista aumentou. Mas, se compararmos o ano de 2014 com 2010, esse índice obteve redução.

Tabela 5 - Media da redução de mortes em Nova York

\begin{tabular}{|l|r|}
\hline \multicolumn{1}{|c|}{ Tipo de usuário } & \% Nova York \\
\hline Bicicleta & $0,48 \%$ \\
\hline Moto & $7,68 \%$ \\
\hline Passageiros de veículos & $-34,71 \%$ \\
\hline Pedestres & $-15,59 \%$ \\
\hline Total & $-19,68 \%$ \\
\hline
\end{tabular}

Utilizando esses dados referentes à redução das mortes em Nova York e aplicando nos resultados referentes às mortes de São Paulo, conseguimos criar o cenário que São Paulo teria, caso as medidas do programa fossem implantadas coerentemente na cidade.

Tabela 6 - Aplicação da redução de mortes de Nova York na cidade de São Paulo

\begin{tabular}{|l|r|r|r|}
\hline \multicolumn{1}{|c|}{ Tipo de usuário } & \% Nova York & $\begin{array}{c}\text { Mortes São Paulo } \\
2014\end{array}$ & $\begin{array}{l}\text { Vidas que seriam } \\
\text { poupadas em São Paulo }\end{array}$ \\
\hline Bicicleta & $0,48 \%$ & 47 & 33 \\
\hline Moto & $7,68 \%$ & 440 & -71 \\
\hline Passageiros de veículos & $-34,71 \%$ & 207 & -86 \\
\hline Pedestres & $-15,59 \%$ & 555 & -245 \\
\hline Total & $-19,68 \%$ & 1249 & \\
\hline
\end{tabular}

Analisando a Tabela 6, podemos verificar que hipoteticamente conseguiríamos reduzir o número de mortes de passageiros de veículos e dos pedestres. Considerando que a maioria das mortes em São Paulo acontece com os pedestres, o modelo de programa Visão Zero ajudaria a evitar 86 mortes.

Uma das medidas que poderia ser utilizada seria o aumento da fiscalização por radares estrategicamente instalados nos semáforos para que motoristas não ultrapassem os sinais 
vermelhos, o que segundo o programa Vision Zero Nova York, reduz $31 \%$ os acidentes com pedestres. Simulando este dado com o número de pedestres mortos em São Paulo em 2014, 172 vidas teriam sido salvas.

\section{CONCLUSÃO}

Analisando os estudos e planos de segurança viária implantado principalmente em Nova York e Estocolmo para a redução de mortes em acidentes de trânsito, fica claro como alternativas bem sucedidas e, de certa forma, aplicáveis no trânsito da cidade de São Paulo.

Os dados do número de acidentes de trânsito em 2014 registrados pela Companhia de Engenharia de Tráfego em São Paulo reforçam a importância e a necessidade de adoção de medidas mitigadoras, que busquem atuar não somente no campo de infraestrutura e fiscalização de trânsito, como na educação de base em escolas públicas e privadas.

Porém, é de extrema importância que o poder público esteja sempre presente, não somente sinalizando, fiscalizando e organizando os deslocamentos, mas também preparando e educando todas as modalidades mais vulneráveis para se locomover, que são, pedestres, ciclistas e motociclistas, que utilizam o espaço viário, tornando suas atitudes mais solidárias no trânsito em conjunto com os automóveis, ônibus e caminhões.

O pensamento sistêmico de infraestrutura, educação e fiscalização deve seguir esta ordem. Isto é, o efeito de aprendizado por meio de fiscalização sem consciência na educação desde o ensino base, não contribui para a redução de mortes. Assim como iniciar um projeto com alterações na infraestrutura, responsabilizando todas as partes envolvidas e não somente os possíveis causadores de acidentes, compartilha o nível de responsabilidade em todas as áreas relacionadas ao trânsito.

Em virtude da utilização da motocicleta no Brasil, e especificamente em São Paulo, por ter comportamentos distintos de cidades como Estocolmo e Nova York, fica prejudicado qualquer comparativo e alternativa de proposta de redução de mortes, sendo necessário um estudo focado neste modal com os demais outros. Deste modo, a segunda fase, conhecida como educação nos 3Es é primordial para o bem comum no compartilhamento da mesma via com os veículos automóveis, ônibus e caminhões. Assim como a redução da velocidade quando há todas estas modalidades e cruzamentos de vias, aumentando o risco de acidentes em função do tempo de reação das partes envolvidas.

Um programa que reduziria também o número de mortes e não foi contabilizado neste estudo, seria a regulamentação do Alcolock para os motoristas condenados por serem pegos com índice de alcoolismo acima do permitido pelo Código de Trânsito Brasileiro.

O trabalho com adolescentes passageiros em serem estimulados a denunciar motoristas negligentes também é uma das alternativas para que a redução de mortes, principalmente entre as idades de 16 a 19 anos, que iniciam na prática a consciência dos valores que tem referente aos perigos envolvidos em acidentes de trânsito, que em tese, já teriam aprendido em sala de aula. 
Em suma, ações simples adotadas na cidade de Nova York poderiam evitar a morte de aproximadamente 245 pessoas no ano de 2014 na cidade de São Paulo, mas que, infelizmente, estamos longe de se chegar neste resultado, visto que os erros iniciam já na permissão de execução de infraestrutura não adequada como a segregação de modais como ônibus e bicicletas, sendo apenas separadas por faixas pintadas. A educação não se aplica na escola e a punição é feita muitas vezes com rigor e sem explicação do porque da penalidade, aumentando o descontentamento e estimulando a burlar os radares de forma cultural e sem consciência da gravidade que faz.

\section{REFERÊNCIAS}

AMBEV S.A (Brasil). Retrato da Segurança Viária no Brasil - 2014. Brasília: Grupo Máquina Pr, 2014. 104 p. Disponível em:

<http://onsv.org.br/portaldados/downloads/retrato2014.pdf>. Acesso em: 09 maio 2015.

ATKINS, Dale; GRANHED, Magnus. VISION ZERO: APPLYING ROAD SAFETY TO AVALANCHE SAFETY. In: INTERNATIONAL SNOW SCIENCE WORKSHOP, ANCHORAGE, 19., 2012, Anchorage. Proceedings... . Anchorage: International Snow Science Workshop, Anchorage, 2012. p. 16 - 22. Disponível em:

<http://arc.lib.montana.edu/snow-science/objects/issw-2012-016-022.pdf>. Acesso em: 26 abr. 2015.

CAMPOS, Cintia Isabel de et al. O panorama do Brasil anterior à Década de Ação pela Segurança Viária 2011-2020. In: CONGRESSO BRASILEIRO DE TRANSPORTE E TRÂNSITO, 19., 2013, Brasília. Anais... . Brasília: Antp, 2013. p. 1 - 8. Disponível em: <http://www.antp.org.br/_5dotSystem/download/dcmDocument/2013/09/16/121C645F-2179 4C53-B55F-E4E5A672D3B9.pdf>. Acesso em: 26 abr. 2015.

Companhia de Engenharia de Tráfego. Acidentes de trânsito fatais. São Paulo: Cet, 2014. Disponível em:

<http://www.cetsp.com.br/media/395294/relatorioanualacidentesfatais2014.pdf >. Acesso em: 16 maio 2015.

ESTADOS UNIDOS. VISION ZERO. . Vision Zero: One Year Report. New York: Vision Zero, 2015. Disponível em:

<http://www.nyc.gov/html/visionzero/assets/downloads/pdf/vision-zero-1-year-report.pdf>. Acesso em: 22 maio 2015.

FRANZ, Cristiane Maria; SEBERINO, Jose Roberto Vieira. A história do trânsito e sua evolução. 2012. 24 f. Monografia (Especialização) - Curso de Gestão, Educação e Direito de Trânsito, Lato Sensu, Joinville, 2012. Disponível em:

<http://www.transitobr.com.br/downloads/a_historia_do_transito_e_sua_evolucao.pdf>. Acesso em: 24 maio 2015.

FREITAS, Juliana Pontes Pinto. Análise dos acidentes de trânsito envolvendo crianças na cidade de Uberlândia: subsídios para as políticas públicas. 2013. 203 f. Tese (Doutorado) 
Curso de Geografia, Universidade Federal de Uberlândia, Uberlândia, 2013. Disponível em: < http://repositorio.ufu.br/handle/123456789/3349>. Acesso em: 15 out. 2014.

POR VIAS SEGURAS. Estatísticas nacionais de acidentes de trânsito. Disponível em: $<\mathrm{http}: / / \mathrm{www}$.vias-seguras.com/os_acidentes/estatisticas/estatisticas_nacionais $>$. Acesso em: 02 dez. 2014.

IRTAD. Road Safety Annual Report 2014: Belgium. França: Oecd, 2014. Disponível em: <http://www.oecd-

ilibrary.org/docserver/download/7514011ec009.pdf?expires $=1432520333 \& \mathrm{id}=\mathrm{id} \&$ accname $=\mathrm{u}$ est\&checksum=4D2371A0FC0AEE9CDB5B569433BAB3B3>. Acesso em: 23 maio 2015.

IRTAD. Road Safety Annual Report 2014: Luxembourg. França: Oecd, 2014. Disponível em: <http://www.oecd-

ilibrary.org/docserver/download/7514011ec028.pdf?expires $=1432520329 \& \mathrm{id}=\mathrm{id} \&$ accname $=$ uest\&checksum=54D3E3F02F2241673C5A9DBA3B83BC23>. Acesso em: 23 maio 2015.

IRTAD. Road Safety Annual Report 2014: Sweden. França: Oecd, 2014. Disponível em: $<$ http://www.oecd-

ilibrary.org/docserver/download/7514011ec030.pdf?expires $=1432520323 \& \mathrm{id}=\mathrm{id} \&$ accname $=$ uest\&checksum=784732B81E1B3033810D492478A21453>. Acesso em: 23 maio 2015.

IRTAD. Road Safety Annual Report 2014: Sweden. França: Oecd, 2014. Disponível em: $<$ http://www.oecd-

ilibrary.org/sweden_5jxt470813g5.pdf?contentType=\&itemId;=/content/chapter/irtad-201439-

en\&mimeType $=$ application/pdf\&containerItemId; $=/$ content/serial/23124571\&accessItemIds; =/content/book/irtad-2014-en>. Acesso em: 16 maio 2015 .

INSTITUTE FOR ROAD SAFETY RESEARCH (Holanda).Advancing Sustainable

Safety: National Road Safety Outlook for 2005-2020. Leidschendam: Slee Communicatie, 2006. Disponível em:

<http://www.swov.nl/rapport/DMDV/Advancing_Sustainable_Safety.pdf >. Acesso em: 25 mar. 2015.

LINDAU, Luis Antonio; OBELHEIRO, Marta; MACHADO, Rafaela. IMPACTOS DA REDUÇÃO DOS LIMITES DE VELOCIDADE EM ÁREAS URBANAS. Porto Alegre: Embarq Brasil, 2015. Disponível em:

$<$ http://www.mobilize.org.br/midias/pesquisas/impactos-da-reducao-dos-limites-develocidade.pdf $>$. Acesso em: 16 maio 2015.

MELLO FILHO, Msc. Luiz Vicente Figueira de. O PONTO DOCE DA SUSTENTABILIDADE NA MOBILIDADE URBANA DA CIDADE DE SÃO PAULO. In: SIMPÓSIO INTERNACIONAL DE ENGENHARIA AUTOMOTIVA, 22., 2014, São Paulo. Proceedings... .São Paulo: Simea 2014, 2014. p. 1 - 17. Disponível em: $<$ http://pdf.blucher.com.br/engineeringproceedings/simea2014/55.pdf >. Acesso em: 20 jan. 2015. 
NEVE, Alice Cristina Medeiros das et al. Sistema de Vigilância de Violências e Acidentes 2009, 2010 e 2011. Brsília: Ministério da Saúde, 2013.

NEW YORK CITY DOT. Motorists \& Parking. Disponível em: $<$ http://www.nyc.gov/html/dot/html/motorist/motorist.shtml >. Acesso em: 09 maio $2015 .$.

OLIVEIRA, Luiz Antonio de. A consolidação, interpretação e aplicação da Lei 11.705/08, na esfera administrativa, quanto no âmbito judicial e sua legalidade. $2013.18 \mathrm{f}$. TCC (Graduação) - Curso de Direito, Universidade Católica de Brasília, Brasília, 2013. Disponível em: 〈http://twingo.ucb.br/jspui/bitstream/10869/2640/1/Luiz Antonio de Oliveira.pdf>. Acesso em: 22 nov. 2013.

Organização Mundial da Saúde. Promovendo a defesa da Segurança Viária e das Vítimas de Lesões Causadas pelo Trânsito: Um guia para organizações não governamentais. Genebra: Organização Mundial da Saúde, 2013. Disponível em: <http://apps.who.int/iris/bitstream/10665/44854/8/9789248503320_por.pdf>. Acesso em: 20 maio 2015.

PAULA, Max Ernani Borges de et al. Acidentes de trânsito fatais: relatório anual 2013. São Paulo: Companhia de Engenharia de Tráfego, 2014. 25 p. Disponível em:

<http://www.cetsp.com.br/media/296383/anuaisfatais2013b.pdf>. Acesso em: 29 set. 2014.

POR VIAS SEGURAS. Estatísticas nacionais de acidentes de trânsito. Disponível em: $<$ http://www.vias-seguras.com/os_acidentes/estatisticas/estatisticas_nacionais>. Acesso em: 02 dez. 2014.

RAIA JUNIOR, Archimedes Azevedo. A responsabilidade pelos acidentes de trânsito segundo a visão zero. Revista dos Transportes Públicos, São Paulo, v. 1, n. 31, p.7-18, jan. 2009. Disponível em:

<http://www.antp.org.br/_5dotSystem/download/dcmDocument/2013/01/10/D216EF54 57BC-484C-8462-84A967FF7696.pdf>. Acesso em: 13 mar. 2015.

RAIA JUNIOR, Archimedes Azevedo. A RESPONSABILIDADE PELOS ACIDENTES DE TRÂNSITO SEGUNDO A VISÃO ZERO. 2009. 28 f. Tese (Doutorado) - Curso de Engenharia Civil, Universida, São Carlo, 2009. Disponível em:

<http://www.sinaldetransito.com.br/artigos/visao_zero.pdf>. Acesso em: 25 abr. 2015.

RAIA JUNIOR, Archimedes Azevedo; SANTOS, Luciano dos. ACIDENTE ZERO: UTOPIA OU REALIDADE? In: CONGRESSO BRASILEIRO DE TRANSPORTE E TRÂNSITO, 15., 2005, Goias. Anais... . Goiânia: Congresso Brasileiro de Transporte e TrÂnsito, 2005. p. 1 - 10. Disponível em: 〈http://www.sinaldetransito.com.br/artigos/acidente_zero.pdf $>$. Acesso em: 13 mar. 2015.

ROCHA, Diego Domingues da; SILVEIRA, JÉssica Silva. ANÁLISE DOS FATORES DE RISCO NO TRÂNSITO NA BR 316 TRECHO MARITUBA. 2013. 67 f. TCC (Graduação) - Curso de Curso de Engenharia Civil, Universidade da AmazÔnia, Belém, 2013. Disponível em: <http://www.unama.br/graduacao/engenharia-civil/tccs/2013/ANÁLISE DOS FATORES DE RISCO NO TRÂNSITO NA BR 316 TRECHO MARITUBA.pdf>. Acesso em: 24 maio 2015. 
SCHOOL OP SEEF (Holanda). Mijn SEEF infopagina:Verkeersveiligheidslabel. Disponível em: 〈http://www.schoolopseef.nl/mijn-seef>. Acesso em: 02 dez. 2014.

SOUZA, Alexandre Gaiofato de; TEIXEIRA, Márcio Holanda; TUMA JUNIOR, Romeu. Sancionada lei que aumenta rigor na punição de infrações de trânsito. Disponível em: <http://www.migalhas.com.br/dePeso/16,MI201643,101048 Sancionada+lei+que+aumenta+rigor+na+punicao+de+infracoes+de+transito>. Acesso em: 02 dez. 2014.

THE VISION ZERO (Sweden). Any loss of life in traffic is unacceptable. Disponível em: <http://www.visionzeroinitiative.com/en/Concept/The-vision-zero/>. Acesso em: 15 maio 2015.

THE VISION ZERO (Sweden). Freedom to move. Disponível em: <http://www.visionzeroinitiative.com/en/Concept/The-vision-zero/>. Acesso em: 15 abr. 2015.

TINGVALL, Claes; HAWORTH, Narelle. Vision Zero - An ethical approach to safety and mobility. In: INTERNATIONAL CONFERENCE ROAD SAFETY \& TRAFFIC ENFORCEMENT, 6., 1999, Melbourne. Proceedings... . Melbourne: International Conference Road Safety \& Traffic Enforcement, 2000. p. 1 - 14. Disponível em: <http://citeseerx.ist.psu.edu/viewdoc/download?doi=10.1.1.476.2985\&rep=rep1\&type=pdf>. Acesso em: 26 abr. 2015.

UNITED NATIONS. Melhoria da segurança rodoviária global: Definição de metas regionais e nacionais de redução de vítimas de acidentes rodoviários. Genebra: United Nations Publication, 2010. Disponível em:

<http://www.unece.org/fileadmin/DAM/trans/roadsafe/docs/Recommendations_2010p.pdf>. Acesso em: 09 maio 2015.

Vision Zero New York. Vision Zero. Disponível em:

<http://www.nyc.gov/html/visionzero/pages/home/home.shtml>. Acesso em: 09 maio 2015.

Vision Zero New York. Vision Zero Action Plan. New York: Vision Zero, 2014. Disponível em: <http://www.nyc.gov/html/visionzero/pdf/nyc-vision-zero-action-plan.pdf >. Acesso em: 16 maio 2015.

WAISELFISZ, Julio Jacobo. Mapa da violência 2012 caderno complementar 2: Acidentes de Trânsito. São Paulo: Instituto Sangari, 2012. Disponível em:

<http://mapadaviolencia.org.br/pdf2012/mapa2012_transito.pdf>. Acesso em: 25 set. 2014.

WINKELBAUER, Martin et al. Melhores práticas de segurança rodoviária. Luxemburgo: Serviço das Publicações da União Europeia, 2010. 64 p. Disponível em:

<http://ec.europa.eu/transport/road_safety/pdf/projects/supreme-c_pt.pdf >. Acesso em: 21 set. 2014

WORLD HEALTH ORGANIZATION (Org.). Road traffic injuries. 2013. Disponível em: <http://www.who.int/mediacentre/factsheets/fs358/en/>. Acesso em: 13 out. 2014 
WORLD HEALTH ORGANIZATION. (Org.). The top 10 causes of death. 2014.

Disponível em: <http://www.who.int/mediacentre/factsheets/fs310/en/>. Acesso em: 13 out. 2014 